\title{
Carbodimide cross-linked and biodegradation-controllable small intestinal submucosa sheets
}

\author{
Ching-Cheng Huang ${ }^{\mathrm{a}, \mathrm{b}}$, Ching-Yi Liu ${ }^{\mathrm{c}}$, Chi-Yen Huang ${ }^{\mathrm{c}}$ and Hsia-Wei Liu ${ }^{\mathrm{c}, *}$ \\ ${ }^{a}$ Department of Biomedical Engineering, Ming-Chuan University, 5 De Ming Rd., Gui Shan District, \\ Taoyuan, 333, Taiwan \\ ${ }^{b}$ Metal Industries Research \& Development Centre, 6F, No. 162-24, Sec. 3, Hsin-Yi Rd., Taipei 10658, \\ Taiwan \\ ${ }^{c}$ Department of Life Science, Fu Jen Catholic University, No. 510, Jhongiheng Rd., Sinjhuang Dist., \\ New Taipei City 24205, Taiwan
}

\begin{abstract}
The small intestinal submucosa (SIS) is an acellular collagen-based matrix, primarily composed of fibrillar collagens (types I, II, and V). They enhance healing due to a minimal immune response. A good degradation rate is the degradation of materials equal to the rate of remodeling in the host. The SIS should apply a good degradation rate and cytocompatibility. In this study, a series of SIS with different degradation rates is obtained by treatment with Ethyl-3-(3dimethylaminopropyl) carbodiimide hydrochloride (EDC). Morphology, composition, degradable ratio, mechanical properties and cytocompatibility of the SIS are evaluated. We determined a $20 \mu \mathrm{m}$ thickness and $60 \mu \mathrm{m}$ pore size of the native SIS. The degradable ratio of the native SIS was approximately $90 \%$ in the presence of $0.25 \mathrm{mg} / \mathrm{ml}$ collagenase for 24 hours. The storage modulus of the native SIS was 388MPa. The degradable ratio of the SIS decreased to $6 \%$ and the storage modulus increased to $777 \mathrm{MPa}$ after being treated with 30mM EDC for 24 hours. In cytocompatibility assay, cell numbers on the native SIS were similar as on the treated SIS due to the non-toxicity of the EDC treatment process. This SIS exhibited collagenase resistance, stronger mechanical strength and good cytocompatibility after the EDC treatment concluded. The crosslinked SIS could be utilized as a potential cell carrier for tissue engineering application.
\end{abstract}

Keywords: Carbodiimide cross-linked, small intestinal submucosa (SIS), biodegradation, cytocompatibility

\section{Introduction}

Numerous materials have been proposed, modified and used for biomedical applications such as scaffolds for skin and bone tissue reconstruction. Synthetic materials, such as polyimide [1], polyamide [2], polyelectrolyte [3-6], polyacrylate [3-7], polynorborene [8-11], polyurethane [12], poly (lactide-co-glycolide), polyglycolide and polylactide have been used either alone or in combination with

\footnotetext{
${ }^{*}$ Corresponding author: Hsia-Wei Liu, Department of Life Science, Fu Jen Catholic University, No. 510, Jhongiheng Rd., Sinjhuang Dist., New Taipei City 24205, Taiwan. Tel.: +886-2-29053740; Fax: +886-2-29052193; E-mail: 079336@mail.fju.edu.tw.
} 
naturally derived materials including collagen, chitosan, starch and silk fibroin [13-25]. These materials are designed to serve as a bone substitute or as an enhancement for the bone-healing process.

Among the several commercially available bone graft materials, collagen-hydroxyapatite composite scaffold is currently the most commonly clinically-used material [24-26]. Recently, a cell-based approach has been proposed as a new concept in bone tissue regeneration. While many biomaterials serve as a scaffold that augments the body's ability to heal itself, a tissue engineering approach uses cells added to a scaffold to achieve the formation of bone tissue.

Some materials may not be suitable for use with cells due to their physical and structural configuration. PLGA has been used as a scaffold for bone tissue engineering due to its favorable physical properties $[25,26]$. A naturally-derived, collagen-based matrix taken from the bladder has been used as a scaffold for multiple applications, including bladder and urethral tissue reconstruction [25,26].

Naturally-derived materials and acellular tissue matrices have various advantages in a biologic environment. Natural collagenous materials showed low antigenicity. Collagen is the most abundant and omnipresent structural protein in the body and may readily be purified from both animal and human tissues.

Collagen has also gained FDA approval for many types of biomedical application [27]. The SIS derived from the submucosa layer of a porcine intestine has already gained FDA approval and is widely used as biomaterial with minimum immune response [27] and can be applied as a biomaterial scaffold for tissue engineering applications to arteries [28,29], the lower urinary tract [30], bone [31], and the abdominal wall [32]. Encouraging results with appropriate tissue regeneration and functional recovery have been reported in each of these applications. Therefore, SIS appears to have the potential to facilitate host tissue regeneration without concurrent immunologic rejection or alteration [28-32].

The SIS consists more than $90 \%$ of types I and III collagens [27]. The SIS contains a wide variety of cytokines such as basic fibroblast growth factor (bFGF), transforming growth factor- $\beta$ (TGF- $\beta$ ), epidermal growth factor (EGF), vascular endothelial growth factor (VEGF), and insulin-like growth factor-1 (IGF-1) as well as glycosaminoglycans, fibronectins, chondroitin sulfates, heparins, heparin sulfates, and hyaluronic acids [27]. These constituents are expected to play an important role as scaffolds in tissue engineering for the generation of tissue and organs. Cell proliferation could be accelerated by cytokines of the SIS [27]. In addition, the SIS can support a suitable surface for cell attachment, proliferation, differentiation, and migration. Therefore, the SIS could act effectively as a scaffold. In this study, new biodegradation-controllable SIS materials have been designed and the characterization and evaluation of native and biodegradation-controllable SIS materials are studied.

\section{Experimental}

\subsection{The preparation of small intestinal submucosa (SIS) materials}

The native small intestinal submucosa (SIS) layer was prepared from the intestines of a New Zealand White Rabbit. To separate the SIS in porcine jejunum, fat is first removed from porcine jejunum, followed by careful washing with water. The porcine jejunum is cut in lengths of approximately $10 \mathrm{~cm}$ and then washed with a saline solution. The SIS was obtained by mechanical removal of the tunica serosa and tunica muscular (Figure 1A). The obtained SIS was washed again with a saline solution. The SIS was prepared by longitudinal cutting in the longitudinal direction, followed by freeze-drying using a freeze dryer at $-80^{\circ} \mathrm{C}$ for 48 hours to provide a native SIS sheet. 


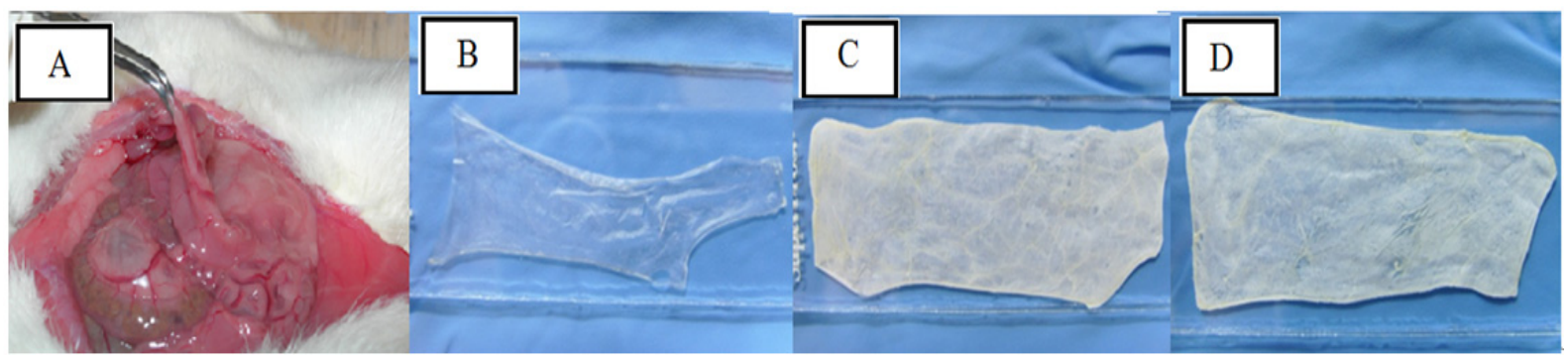

Fig. 1. (A)Native SIS layer prepared from the intestines of New Zealand White Rabbit and three different thickness of EDCcrosslinked SIS layer (B) $<4 \mu \mathrm{m}$, (C) $4-6 \mu \mathrm{m}$ and (D) $>6 \mu \mathrm{m}$.

\subsection{The preparation of cross-linked small intestinal submucosa (SIS) materials}

EDC (1-ethyl-3-(3-dimethylaminopropyl) carbodiimide hydrochloride) was employed in the preparation of cross-linked SIS materials. The SIS sheets were cross-linked with EDC in the concentration of $10 \mathrm{mM}, 20 \mathrm{mM}$ and $30 \mathrm{mM}$. To make a chemical cross-linked SIS layer (Figures 1B-1D), the native SIS layer was immersed in $2 \mathrm{ml}$ of $50 \mathrm{mM} 2$-(N-morpholino) ethanesulfonic acid in $40 \%$ ethanol (pH 5.0) with $10 \mathrm{mM}, 20 \mathrm{mM}$ or $30 \mathrm{mM}$ 1-ethyl-3-(3-dimethylaminopropyl) carbodiimide hydrochloride and $6 \mathrm{mM} \mathrm{N}$-hydroxysuccinimide at $4{ }^{\circ} \mathrm{C}$ for 4,12 and 24 hours.

\subsection{The scanning electron microscopic study of SIS}

A scanning electron microscope was used to examine the structure of the native and cross-linked SIS layer. A scanning electron microscope (SEM, S-2250N, Hitachi, Japan) was used to examine the structure of the prepared SIS sheets. SIS sheets were cut in vertical sections. The samples were mounted on metal stubs and coated with a thin layer of platinum using a plasma-sputtering apparatus (Model SC $500 \mathrm{~K}$, Emscope, UK) for two minutes under an argon atmosphere.

\subsection{In vitro biodegradation of SIS sheets}

Native and cross-linked SIS layers were evaluated for biodegradation in the absence and presence of $10 \mathrm{mg} / \mathrm{mL}$ collagenase solution. The SIS sheets were washed by deionized water several times and dried by the freeze dryer at a set date. Then, they were weighed to determine the weight loss from the original SIS sheets. The weight loss experiment was individually performed in three SIS sheets and then calculated as an average value.

\subsection{Mechanical properties of SIS sheets}

The mechanical properties of designed SIS sheets could be studied and characterized by the determination of storage modulus (Dynamic Mechanical Analyzer, TA2980 DMA) of native SIS sheets and different cross-linked SIS sheets. These were prepared by an additional cross-linked reaction with 10 $\mathrm{mM}, 30 \mathrm{mM}$, and $50 \mathrm{mM}$ EDC for 24 hours. 


\subsection{Cell-seeded SIS sheets in vitro}

The mouse fibroblast L929 cells (ATCC number: CCL-1) were maintained at $37^{\circ} \mathrm{C}$ in a humidified atmosphere of $5 \% \mathrm{CO}_{2}$ in DMEM supplemented with $10 \%$ FBS and $1 \%$ PSA $(10000 \mathrm{unit} / \mathrm{mL}$ penicillin, $10 \mathrm{mg} / \mathrm{mL}$ streptomycin, $0.025 \mathrm{mg} / \mathrm{mL}$ amphotericin). All the cells in this experiment were preceded within ten passages. To evaluate cell behavior relative to the microstructure of SIS sheets, the sheets were pre-wet by submerging them in filtered $70 \%$ ethanol for thirty minutes, rinsed in sterile phosphate-buffered saline for one hour, and treated with ultraviolet light overnight. L929 cells were subsequently loaded onto SIS sheets at a concentration of $1 \times 10^{3}$ cells $/ \mathrm{ml}$ on 24 -well plates and cultured in a humidified $5 \% \mathrm{CO}_{2}$ incubator at $37^{\circ} \mathrm{C}$ for 24 hours. The cell-seeded SIS sheets were then characterized by means of MTT assay, live/dead cell viability/cytotoxicity kit (L-3224; Molecular Probes, Eugene, Ore) and morphological study using SEM.

\section{Results and discussion}

\subsection{Fabrication and architecture of designed SIS sheets}

The New Zealand white rabbits were employed for a preparation of SIS sheets. The scanning electron microscopic view of native SIS showed a rough outer surface and smooth inner surface (Figure 2A). The native SIS sheet was approximately $5.21 \pm 0.46 \mu \mathrm{m}$ in thickness. The mean chamber or pore diameter was approximately $60 \mu \mathrm{m}$. Furthermore, a new biodegradation-controllable SIS material was designed and EDC was employed in the preparation of cross-linked SIS materials as a cross-linking agent. After the cross-linking reaction of SIS sheets with EDC, new biodegradation-controllable SIS materials were obtained (Figure 2B). The structure of cross-linked SIS sheets consists of the multiple pores or chamber walls with $5.05 \pm 1.35 \mu \mathrm{m}$ thickness (Figure $2 \mathrm{C}$ ).

\subsection{Collagenase resistance and biodegradation of newly designed SIS sheets}

Biodegradation of cross-linked-SIS sheets has been evaluated by using collagenase within Hank's solution. The photos of the evaluation of native SIS sheets and cross-linked SIS sheets are shown in Figure 3. Figures 3A-3C show a native SIS sheet within Hank's solution with $10 \mathrm{mg} / \mathrm{mL}$ collagenase for 2 hours, 12 hours and 24 hours. The remarkable degradation of a native SIS sheet within Hank's

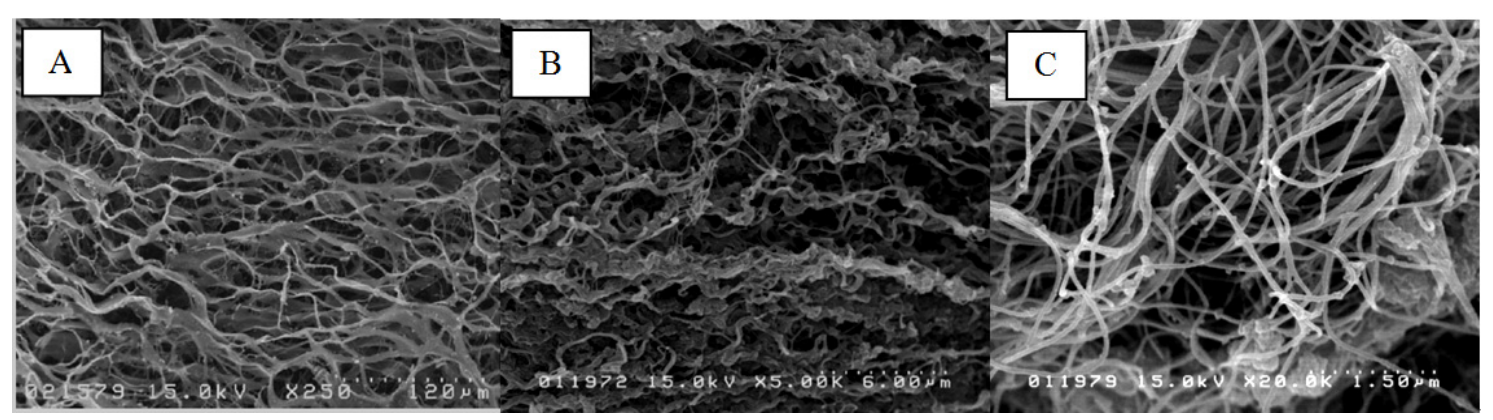

Fig. 2. SEM photographs of native SIS sheets: (A) rough outer surface $(\times 250)$, (B) cross-linked SIS with $30 \mathrm{mM}$ EDC for $24 \mathrm{~h}(\times 5 \mathrm{~K})$ and $(\mathrm{C})$ smooth inner surface $(\times 20 \mathrm{~K})$. 


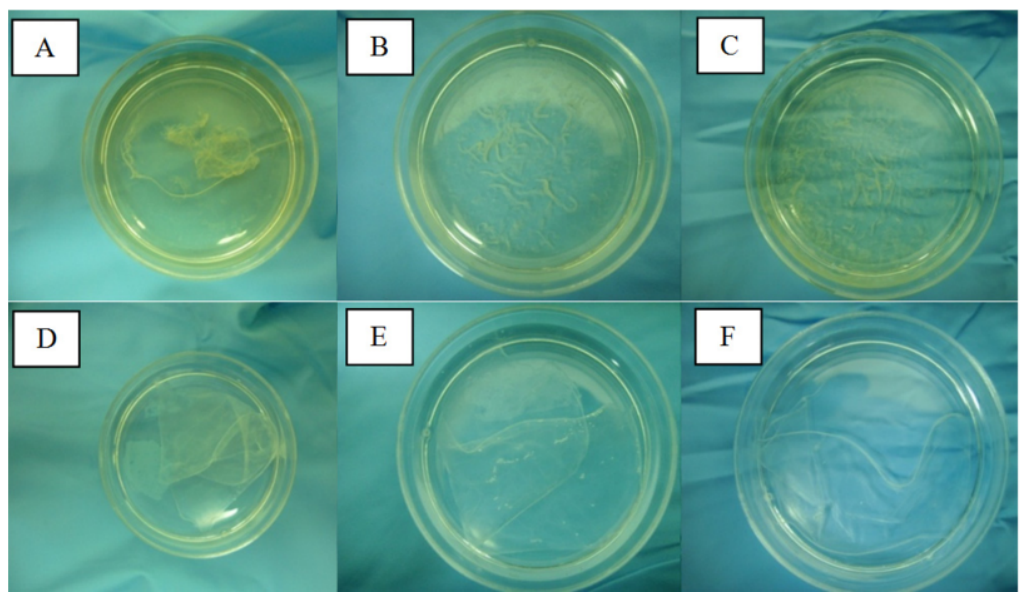

Fig. 3. Photos of a native SIS (NSIS) sheet, a native SIS (NSIS) sheet within Hank's solution with $10 \mathrm{mg} / \mathrm{ml}$ collagenase for 2 hours (A), 12 hours (B) and 24 hours (C); CLSIS2 within Hank's solution with $10 \mathrm{mg} / \mathrm{ml}$ collagenase for 2 hours (D); and CLSIS3 within Hank's solution with $10 \mathrm{mg} / \mathrm{ml}$ collagenase for 2 hours (E) and 24 hours (F).

solution can be observed. Figures 3D-3F show cross-linked SIS sheets within Hank's solution with 10 $\mathrm{mg} / \mathrm{m}$. The degradation of cross-linked SIS sheets is not remarkable. Relatively high concentration of EDC was employed for the preparation of the highly cross-linked structure of new SIS materials. When the degradation of cross-linked SIS sheets has occurred, the swelling of new SIS materials can be observed. The native SIS sheet or scaffold was degraded over $80 \%$ at 2 hours. After 24 hours, the biodegradation rate of the native SIS sheet was over $90 \%$. Relatively, the cross-linked SIS sheets or scaffolds showed lower biodegradation rates than $40 \%$ at 2 hours for CLSIS4, CLSIS5, CLSIS6, CLSIS7, CLSIS8, and CLSIS9 (Figures 4A and 4B). The values of CLSIS4, CLSIS5, CLSIS6, CLSIS7, CLSIS8, and CLSIS9 were observed at $40 \%, 28 \%, 10 \%, 39 \%, 26 \%$, and $4 \%$ respectively (Figures 4A and 4B). These might be due to the longer cross-linking times and more highly concentrated EDC concentrations (Table 1). This results in stronger and more stable constructs. The biodegradation of cross-linked SIS sheets or scaffolds would be carried out with more difficulty.

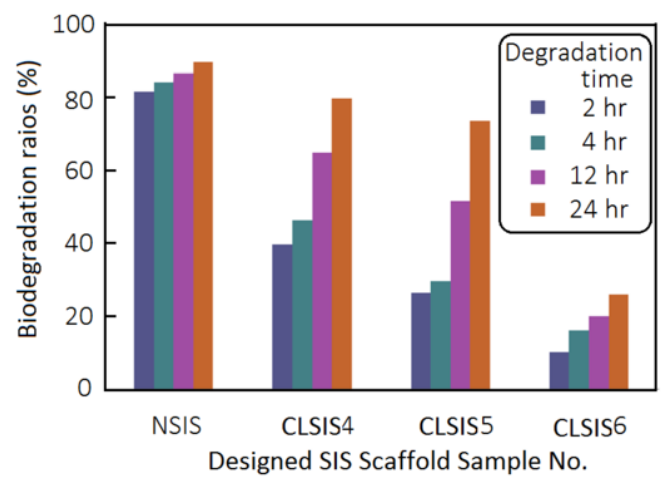

(A)

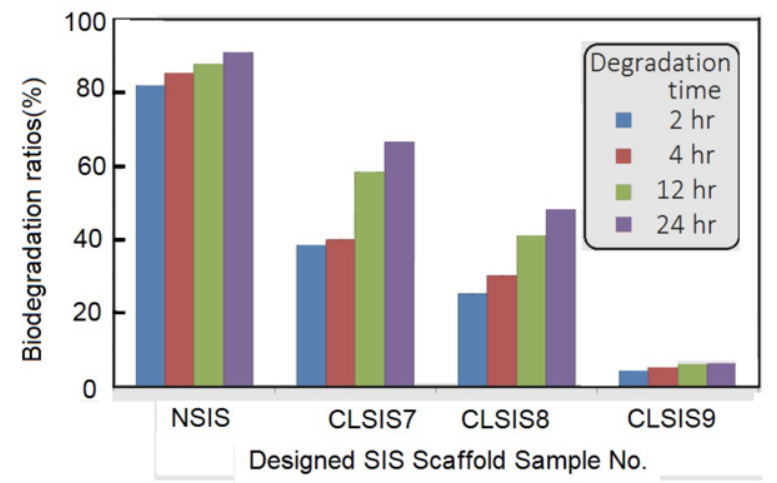

(B)

Fig. 4. The biodegradation ratio (A) of the native SIS sheet, cross-linked SIS sheets (LCSIS4, LCSIS5, and LCSIS6) with 10 $\mathrm{mM}$ EDC for various cross-linking reaction time of 4, 12, and 24 hours, and (B) cross-linked SIS sheets (LCSIS7, LCSIS8, and LCSIS9) with $30 \mathrm{mM}$ EDC for various cross-linking reaction time of 4, 12, and 24 hours. 
Table 1

Newly Designed SIS Scaffolds

\begin{tabular}{lll}
\hline Sample No. & EDC $^{*}$ & Cross-linking time \\
\hline NSIS & 0 & 0 \\
CLSIS 1 & $10 \mathrm{mM}$ & $2 \mathrm{hr}$ \\
CLSIS 2 & $20 \mathrm{mM}$ & $2 \mathrm{hr}$ \\
CLSIS 3 & $30 \mathrm{mM}$ & $2 \mathrm{hr}$ \\
CLSIS 4 & $10 \mathrm{mM}$ & $4 \mathrm{hr}$ \\
CLSIS 5 & $10 \mathrm{mM}$ & $12 \mathrm{hr}$ \\
CLSIS 6 & $10 \mathrm{mM}$ & $24 \mathrm{hr}$ \\
CLSIS 7 & $30 \mathrm{mM}$ & $4 \mathrm{hr}$ \\
CLSIS 8 & $30 \mathrm{mM}$ & $12 \mathrm{hr}$ \\
CLSIS 9 & $30 \mathrm{mM}$ & $24 \mathrm{hr}$ \\
CLSIS 10 & $50 \mathrm{mM}$ & $24 \mathrm{hr}$ \\
\hline Note: *DC (1-ethyl-3-(3-dimethylaminopropyl) carbodiimide hydrochloride).
\end{tabular}

\subsection{Mechanical properties of designed SIS sheets}

The mechanical properties of the designed SIS sheets have been studied by the determination of storage modulus of native SIS sheets and different cross-linked SIS sheets, which were prepared by additional cross-linked reactions with $10 \mathrm{mM}, 30 \mathrm{mM}$, and $50 \mathrm{mM}$ EDC for 24 hours. A series of newly designed SIS sheets, such as CLSIS6, CLSIS9, and CLSIS10, were obtained. The cross-linking degree of resulting SIS sheets changed with the concentration of cross-linking agents. In general, the degree of cross-linking of resulting SIS sheets increased with the concentration of cross-linking agents. Relatively compacted cross-linked structures of the designed SIS sheets can be obtained and relative good mechanical properties can be observed. The values of storage modulus increased with the concentration of cross-linking agents. As shown in Figure 5A, newly designed SIS sheets of CLSIS6, CLSIS9, and CLSIS10 show the storage modulus of 388, 568, 720, and $777 \mathrm{MPa}$, respectively.

\subsection{Cytocompatibility evaluation of designed cross-linked SIS sheets}

Cytocompatibility evaluation of designed cross-linked SIS sheets can be studied by MTT assay. In cytocompatibility assay, the cell number of native SIS is similar to cross-linked SIS sheets due to the non-toxicity of EDC treatment process.

Survival of L929 cells can be observed with native SIS sheets and cross-linked SIS sheets (CLSIS6, CLSIS9, and CLSIS10) after 24 hours of incubation (Figure 5B). There is remarkable difference in Figure 5B. Cells cultured on the cross-linked SIS sheets suggest relatively maintained cytocompatibility after seeding. 


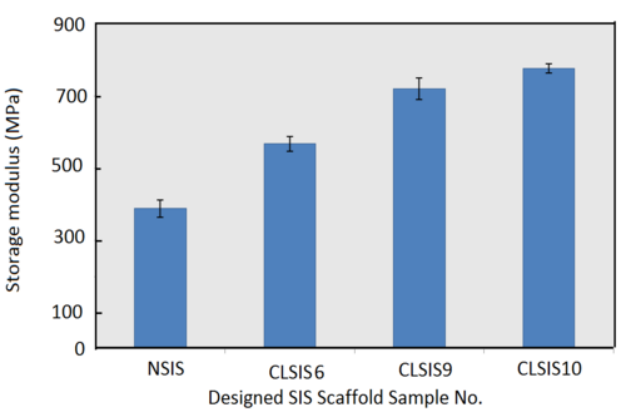

(A)

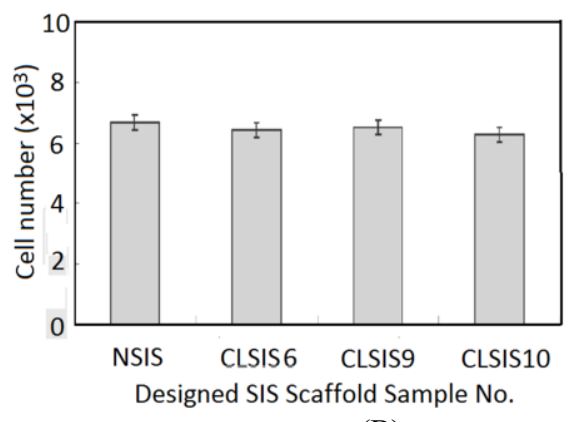

(B)

Fig. 5. (A) The storage modulus of native SIS sheet and cross-linked SIS sheets (CLSIS6, CLSIS9, and CLSIS10) with 10 $\mathrm{mM}, 30 \mathrm{mM}$, and $50 \mathrm{mM}$ EDC for 24 hours. $(\mathrm{p}<0.05)$; and (B) Cytocompatibility evaluation of native SIS sheets and crosslinked SIS sheets (CLSIS6, CLSIS9, and CLSIS10) with $10 \mathrm{mM}, 30 \mathrm{mM}$, and $50 \mathrm{mM}$ EDC after 24 hours of incubation $(\mathrm{p}<0.05)$.

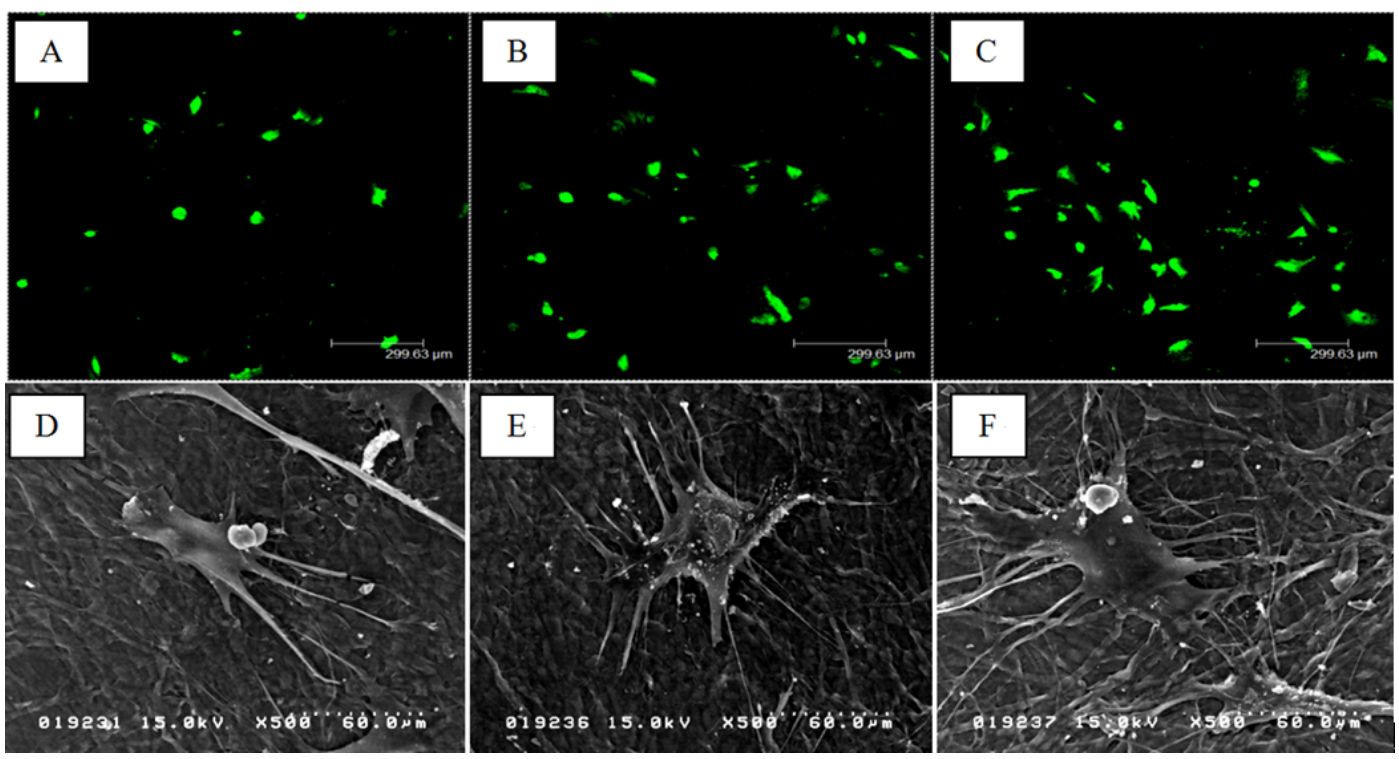

Fig. 6. L929-seeded onto carbodiimide cross-linked SIS sheets and co-cultured after 4 hours (A), 8 hours (B), and 24 hours (C) were stained with a live/dead cell viability assay (original magnification, $\times 10$ ), where living cells fluoresce green. SEM photographs of L929 morphology observed on thesis sheets. Panel D shows the cross-linked SIS sheet at 4 hours; note the fully spread polygonal cells on the wall. Panel E shows the cross-linked SIS sheet at 8 hours; note the interconnected cell filopodia equally distributed throughout the surface. Panel F shows the cross-linked SIS sheet at 24 hours; note that the individual cells have migrated and are surrounded by a newly synthesized pericellular matrix.

\subsection{Cell viability and morphology of L929-seeded SIS sheets}

Figures 6A-6C show confocal laser scanning of microscopic projection images of L929-seeded onto carbodiimide cross-linked SIS sheets. In the carbodiimide cross-linked SIS sheets, the majority of L929 are green, demonstrating viability. Visual examination reveals that the live cells on the SIS sheets after 24 hours are denser than those in the 4- and 8-hour co-culture and have increased cell aggregation. This observational finding indicates that the cells have vitally proliferated. The native SIS derived from the submucosa layer of porcine intestine has already gained FDA approval and is widely 
applied as a biomaterial scaffold for tissue engineering applications to the artery, the lower urinary tract, bone, and abdominal wall [27-32]. In this study, a series of new carbodiimide cross-linked SIS sheets were prepared. Upon scanning electron microscopy, the carbodiimide cross-linked SIS sheet (Figures 6D-6F) has a uniformly distributed and irregular network structure. The surface morphology of the carbodiimide cross-linked SIS sheet (CLSIS9) exhibited a fine texture covering the surface of the sheet after a 4 and 8 hour co-culture (Figures 6D and 6E). Microsponges of extracellular matrix on the cross-linked SIS sheet with interconnected pore structures formed on the surface of a sheet after a 24 hour co-culture (Figure 6F). View of the cross-linked SIS sheets clearly reveals flake-like shapes around the pore walls. The porosity decreased slightly after the EDC cross-linking.

\section{Conclusion}

The SIS provides both the 3-D environment and released growth factors to cells. The greatest feature of the SIS is its ability to deliver a variety of growth factors to cells. Moreover, the SIS promotes cell proliferation and differentiation, and induces the synthesis of a new ECM structurally. The carbodiimide cross-linked and biodegradation-controllable SIS sheets are promising bioactive materials that could potentially serve as a temporary scaffold for tissue engineering. Newly designed biodegradation-controllable SIS sheets composed of biodegradable nanopores or chambers that possess necessary characteristics for tissue regeneration were successfully designed and prepared.

\section{Acknowledgement}

The authors thank Fu Jen Catholic University for financially supporting this research under contract No. 409931044028.

\section{References}

[1] S. Ito, M. Hashimotob, B. Wadgaonkar, N. Svizero, R.M. Carvalho, C. Yiu, F.A. Rueggeberg, S. Foulger, T. Saito, Y. Nishitanii, M. Yoshiyamai, F.R. Tay and D.H. Pashley, Effects of resin hydrophilicity on water sorption and changes in modulus of elasticity, Biomaterials 26 (2005), 6449-6459.

[2] D.J. Liaw, C.C. Huang and B.Y. Liaw, Synthesis and properties of polyurethanes based on bisphenol-s derivatives, Polymer 39 (1998), 3529-3535.

[3] D.J. Liaw, C.C. Huang and W.H. Chen, Color lightness and highly organosoluble polyamides, polyimides and poly (amide-imide)s based on noncoplanar 2, 2'-dimethyl-4, 4'-biphenylene units, Polymer 47 (2006), 2337-2348.

[4] D.J. Liaw, C.C. Huang, H.C. Sang and P.L. Wu, Macromolecular microstructure, reactivity ratio and viscometric studies of water-soluble cationic and/or zwitterionic copolymers, Polymer 41 (2000), 6123-6131.

[5] D.J. Liaw and C.C. Huang, Synthesis and characterization of the poly (sulfobetaine)s and the corresponding cationic polymers derived from n,n'-dialkylamino phenyl methacrylamide, Macromol. Chem. Phys. 201 (2000), 1101-1107.

[6] D. J. Liaw, C.C. Huang, H.C. Sang and E.T. Kang, Intramolecular hydrophobic aggregation of amphiphilic polysulfobetaine with various hydrophobic groups in aqueous solution, Langmuir 15 (1999), 5204-5211.

[7] D.J. Liaw, C.C. Huang, W.F. Lee, J. Borbély and E.T. Kang, Synthesis and characteristics of the poly (carboxybetaine)s and the corresponding cationic polymers, J. Polym. Sci., Part A: Polym. Chem. 35 (1997), 3527-3536.

[8] D.J. Liaw, T.P. Chen and C.C. Huang, Self-assembly aggregation of highly stable copolynorbornenes with am-phiphilic architecture via ring-opening metathesis polymerization, Macromolecules 38 (2005), 3533-3538.

[9] D.J. Liaw, C.C. Huang, S.M. Hong, W.H. Chen, K.R. Lee and J.Y. Lai, Molecular architecture effect on active structure of polynorbornenes with pendant $\alpha, \beta$-unsaturated amide or ester bridged chains via ring-opening metathesis polymerization, Polymer 47 (2006), 4613-4621. 
[10] D.J. Liaw, C.C. Huang and E.T. Kang, Novel fluorescent polynorbornenes with multi-functional armed structure by using highly stable block macroinitiators via a combination of living ring-opening metathesis polymerization and atom transfer radical polymerization, Polymer 37 (2006), 3057-3064.

[11] D.J. Liaw, C.C. Huang and S.M. Hong, Novel doubly polymerizable functional norbornene: Synthesis, reactivity and its macromolecular architectures from dual cure via ring-opening metathesis polymerization and radical photopolymerization, J. Polym. Sci., Part A: Polym. Chem. 44 (2006), 6287-6298.

[12] D.J. Liaw, C.C. Huang and B.Y. Liaw, Synthesis and properties of polyurethanes based on bisphenol-s derivatives, Polymer 39 (1998), 3529-3535.

[13] G. Zhai, S.C. Toh, W.L. Tan, E.T. Kang, K.G. Neoh, C.C. Huang and D.J. Liaw, Poly (vinylidene fluoride) with grafted zwitterionic polymer side chains for electrolyte-responsive microfiltration membranes, Langmuir 19 (2003), 70307037.

[14] X. Jiang, S.H. Lim, H.Q. Mao and S.Y. Chew, Current applications and future perspectives of artificial nerve conduits, Experimental Neurology 223 (2010), 86-101.

[15] T. Katsumata, M. Maitani, C.C. Huang, M. Shiotsuki and T. Masuda, Synthesis and properties of various poly (diphenylacetylenes) containing tert-amine moieties, Polymer 49 (2008), 2808-2816.

[16] C. Silve, E. Lopez, B. Vidal and D.C. Smith, Nacre initiates biomineralization by human osteoblasts maintained in vitro. Calcif. Tissue Int. 51(1992), 363-369.

[17] E.T. Kang, K.G. Neoh, W. Chen, K.L. Tan, D.J. Liaw and C.C. Huang, Surface structures and adhesion charac-teristics of poly (tetrafluoroethylene) films after modification by graft copolymerization, J. Adhesion Sci. Technol. 10 (1996), $725-743$.

[18] Z.F. Li, E.T. Kang, K.G. Neoh, K.L. Tan, C.C. Huang and D.J. Liaw, Surface structures and adhesive-free ad-hesion characteristics of polyaniline films after modification by graft copolymerization, Macromolecules 30 (1997), 33543362.

[19] W. Chen, K.G. Neoh, E.T. Kang, K.L. Tan, D.J. Liaw and C.C. Huang, Surface modification and adhesion characteristics of polycarbonate films after graft copolymerization, J. Polym. Sci., Part A: Polym. Chem. 36 (1998), 357-366.

[20] G. Zhai, S.C. Toh, W.L. Tan, E.T. Kang, K.G. Neoh, C.C. Huang and D.J. Liaw, Poly (vinylidene fluo-ride) with grafted zwitterionic polymer side chains for electrolyte-responsive microfiltration membranes, Langmuir 19 (2003), 70307037.

[21] G. Atlan, O. Delatre, S. Berland, A. Le Faou, G. Nabias, D. Cot and E. Lopez, Interface between bone and nacre implants in sheep, Biomaterals 20 (1997), 1017-1022.

[22] J.E. Barralet, L. Grover, T. Gaunt, A.J. Wright and I.R. Gibson, Preparation of macroporous calcium phosphate cement tissue engineering scaffold, Biomaterials 23 (2002), 3063-3072.

[23] J.M. Karp, M.S. Shoichet and J.E. Davies, Bone formation on twodimensional poly (DL-lactide-co-glycolide) (PLGA) films and three dimensional PLG shoichet, a tissue engineering scaffolds in vitro, J. Biomed. Mater. Res. A 64 (2003), 388-396.

[24] J.A. Roether, J.E. Gough, A.R. Boccaccini, L.L. Hench, V. Maquet and R. Jerome, Novel bioresorbable and bioactive composites based on bioactive glass and polylactide foams for bone tissue engineering, J. Mater. Sci. Mater. Med. 13 (2002), 1207-1214.

[25] H.J. Kim, U.J. Kim, G. Vunjak-Novakovic, B.H. Min and D.L. Kaplan, Influence of macroporous protein scaffolds on bone tissue engineering from bone marrow stem cells, Biomaterials 26 (2005), 4442-4452.

[26] S.J. Lee, G.J. Lim, J.W. Lee, A. Atala and J.J. Yoo, In vitro evaluation of a poly (lactide- co -glycolide)-collagen composite scaffold for bone regeneration, Biomaterials 27 (2006), 3466-3472.

[27] H.H. Ahn, K.S. Kim, J.H. Lee, M.S. Lee, I.B. Song, M.H. Cho, Y.N. Shin, M.S. Kim, G. Khang and H.B. Lee, Porcine small intestinal submucosa sheets as a scaffold for human bone marrow stem cells, International Journal of Biological Macromolecules 41 (2007), 590-596.

[28] Y. Su, B.F. Zeng, C.Q. Zhang, K.G. Zhang and X.T. Xie, Study of biocompatibility of small intestinal submucosa (SIS) with Schwann cells in vitro, Brainresearch 1145 (2007), 41-47.

[29] S.F. Badylak, G.C. Lantz, A. Coffey and L.A. Geddes, Small intestinal submucosa as a large diameter vascular graft in the dog, J. Surg. Res. 47 (1989), 74-80.

[30] F. Campodonico, R. Benelli, A. Michelazzi, E. Ognio, C. Toncini and M. Maffezzini, Bladder cell culture on small intestinal submucosa as bi-oscaffold: Experimental study on engineered urothelial grafts, Eur. Urol. 46 (2004), 531-537.

[31] M.A. Suckow, S.L. Voytik-Harbin, L.A. Terril and S.F. Badylak, Enhanced bone regeneration using porcine small intestinal submucosa, J. Invest. Surg. 12 (1999), 277-287.

[32] F. Zhang, J. Zhang, S. Lin, T. Oswald, W. Sones, Z. Cai, W. Dorsett-Martin and W.C. Lineaweaver, Small intestinal submucosa in abdominal wall repair after TRAM flap harvesting in a rat model, Plast. Reconstr. Surg. 112 (2003), 565570 . 